\title{
Intercalary reconstruction of femur after tumour resection: is a vascularized fibular autograft plus allograft a long-lasting solution?
}

\author{
D. A. Campanacci, F. Totti, S. Puccini, G. Beltrami, G. Scoccianti, L. Delcroix, \\ M. Innocenti, R. Capanna
}

This is the accepted version of an article published in The bone and joint journal 2018, 100:378386, DOI: 10.1302/0301-620X.100B3.BJJ-2017-0283.R2

\begin{abstract}
Aims

After intercalary resection of a bone tumour from the femur, reconstruction with a vascularized fibular graft (VFG) and massive allograft is considered a reliable method of treatment. However, little is known about the long-term outcome of this procedure. The aims of this study were to determine whether the morbidity of this procedure was comparable to that of other reconstructive techniques, if it was possible to achieve a satisfactory functional result, and whether biological reconstruction with a VFG and massive allograft could achieve a durable, long-lasting reconstruction.
\end{abstract}

\section{Patients and methods}

A total of 23 patients with a mean age of 16 years (five to 40 ) who had undergone resection of an intercalary bone tumour of the femur and reconstruction with a VFG and allograft were reviewed clinically and radiologically. The mean follow-up was 141 months (24 to 313). The mean length of the fibular graft was $18 \mathrm{~cm}$ (12 to 29). Full weight-bearing without a brace was allowed after a mean of 13 months (seven to 26).

\section{Results}

At final follow-up, the mean Musculoskeletal Tumor Society Score of 22 evaluable patients was $94 \%$ (73 to 100). Eight major complications, five fractures (21.7\%), and three nonunions $(13 \%)$ were seen in seven patients $(30.4 \%)$. Revision-free survival was $72.3 \%$ at five, ten, and 15 years, with fracture and nonunion needing surgery as failure endpoints. Overall survival, with removal of allograft or amputation as failure endpoints, was $94.4 \%$ at five, ten, and 15 years.

\section{Discussion}

There were no complications needing surgical revision after five years had elapsed from surgery, suggesting that the mechanical strength of the implant improves with time, thereby decreasing the risk of complications. In young patients with an interca- 
lary bone tumour of the femur, combining a VFG and massive allograft may result in a reconstruction that lasts a lifetime.

The femur is a common site in which to find a primary bone tumour. In most cases, the metaphysis and/or epiphysis are involved and an articular reconstruction is required, for which a modular or composite prosthesis is considered to be the best solution.(1)

In recent decades, due to advances in neoadjuvant chemotherapy for malignant bone tumours, more conservative resections have become possible. After the introduction of MRI in the early 1980s, the 3D extent of the tumour could be accurately assessed and the number of intercalary resections that spared the epiphysis increased.

Several reconstructive procedures have been used to treat large intercalary bony defects in the femur. These include bone transport, $(2,3)$ intercalary prostheses, $(4,5)$ massive allografts, $(6,7)$ vascularized autografts, $(8,9)$ and the combined use of allografts and vascularized autografts.(10-16)

Vascularized bone grafting has been widely used to reconstruct parts of the skeleton including the maxilla, spine, pelvis, and long bones.(17-21) The first reported case of using a vascularized fibular graft (VFG) to salvage an injured limb was from Taylor et al(22) in 1975. In 1977, Weiland et al(23) described the first VFG reconstruction of a long bone after resection of a tumour.

Biological reconstruction of the femur using bone graft rather than a prosthesis is an effective method of treatment after an intercalary resection for bone tumour.(6) Vascularized fibular grafting is an established method of treating an intercalary defect in a long bone. It can be used alone or in association with massive allografts or allogenic cortical struts.(8-16) A VFG is commonly used alone in reconstruction of the arm, while in the leg, because of the high mechanical stresses, it is usually used

in conjunction with an allograft to improve primary mechanical stability.(10) The original technique of VFG/allograft reconstruction in the leg was described by $\mathrm{Ca}$ panna et al(24) in 1993. Since then, several authors have reported the results of this technique to reconstruct the femur and tibia.(10-16) However, to our knowledge, thisstudy is the largest series of VFG/allograft primary reconstructions of the femur after resection of a bone tumour from a single hospital.

The purpose of this study was to undertake a retrospective review of our series of VFG and allograft reconstructions of the femur after resection for a bone tumour, with the aim of answering the following questions. First, is the morbidity of the procedure comparable to other reconstructive options for intercalary defects of the femur? Second, is it possible to achieve a satisfactory functional result? Third, does the use of a VFG and allograft result in a durable and long-lasting reconstruction of the femur after intercalary resection? 


\section{Patients and methods}

A total of 24 patients were treated at our hospital (Azienda Ospedaliera Universitaria Careggi) between 1990 and 2016 for a bone tumour that was managed by intercalary resection of the femur and primary reconstruction with a VFG and massive allograft. Of these, 23 were available for evaluation after a minimum of two years and were included in the study. They were retrospectively reviewed and their characteristics are summarized in Table I.

There were 15 males and eight females with a mean age of 16 years (five to 40). The diagnosis was a malignant bone tumour in 22 cases (eleven osteosarcoma, eight Ewing's sarcoma, two chondrosarcoma, and one leiomyosarcoma) and a desmoid tumour in one case. Of the 23 patients, 19 underwent pre- and postoperative chemotherapy. None of the patients were treated with radiotherapy. On histological examination of the resected tumour, the surgical margins were wide in all cases. In all, 22 resections were performed through a lateral approach to the thigh; in 14 cases, an additional medial approach was used to facilitate microsurgical anastomosis of the vascular pedicle. A single medial approach was used in only one patient. Arterial and venous anastomoses were achieved in every case to one of the following recipient vessels: a collateral branch of the superficial femoral artery, a collateral branch of the profunda femoral artery, or a circumflex artery. The mean length of the fibular graft was $18 \mathrm{~cm}$ (12 to 29). The VFG was harvested from the contralateral limb by a microsurgical team of surgeons using separate instruments, taking care to avoid contamination between the two surgical fields. No distal tibiofibular fixation was undertaken on the donor side. The harvested fibula was at least $2 \mathrm{~cm}$ longer than the length of the femoral resection in order to allow a minimum overlap of $1 \mathrm{~cm}$ for each osteotomy. Skeletal fixation was carried out using a bridging plate in 20 cases, a proximal plate and distal screws in two cases, and with screws alone in one case. Our policy was to maintain an intraosseous margin of at least $1 \mathrm{~cm}$ in periarticular resections. In the distal femur of a growing child, when the tumour involved the metaphysis and extended to, but not through, the growth plate, we carried out an intraepiphyseal resection, removing the growth plate with the tumour. The growth plate of the distal femur was preserved when there was enough residual healthy metaphyseal bone to allow for fixation of intercalary allograft and VFG reconstruction. In a periarticular resection, even though the growth plate was preserved, bridging plate fixation (from epiphysis to diaphysis) was used on most occasions to provide adequate mechanical stability, which inevitably impaired growth plate function. In these cases, the epiphyseal screws were removed once the graft had united allowing the growth plate to resume growth.

Three different methods of assembling the VFG-allograft were used (Fig. 1):

A) the allograft was left intact and the VFG placed medially and fixed with screws, overlapping both allograft-host bone osteotomies; 
B) the allograft was left intact and reamed to accept the VFG inside the medullary canal, and an oval window was created in the cortex of the allograft to allow passage of the vascular pedicle;

or C) a longitudinal groove was created in the cortex of the allograft using a highspeed burr. This was of sufficient size to receive the VFG in the medullary canal in a concentric assembly.

In all, ten patients had a type A reconstruction, seven patients had a type B reconstruction, and six patients had a type $\mathrm{C}$ reconstruction (Figs 2 to 4 ).

Each patient was started preoperatively on antibiotic prophylaxis with vancomycin and tobramycin; this continued postoperatively until the drains had been removed. Controlled passive movements of the hip and knee were then allowed. The donor leg was left free postoperatively; active and passive movements of the knee, ankle, and toes were encouraged. Full weight-bearing on the donor side was allowed at three weeks from surgery. One month after surgery an articulated ischial-bearing knee brace was applied so that the patient could walk partially weightbearing. Full weightbearing in the brace was started as soon as the vascularized fibular graft was seen to be radiologically united. The brace was kept on until the allograft had united and initial hypertrophy of the vascularized fibula was evident. Full weight-bearing without the brace was allowed after a mean of 13 months (seven to 26). It occurred between six months and one year in ten cases, between one and two years in 11 cases, and after two years in two cases.

All patients underwent clinical and radiological examination at follow-up. The functional result was evaluated by an orthopaedic surgeon (FT, SP, GB, or GS) who considered pain, function, emotional acceptance, support, walking ability, and gait using the modified 30-point scoring system of the Musculoskeletal Tumor Society (MSTS93) for the leg.25 Union, fracture, and failure of the implant were also assessed radiologically in each patient until final follow-up. Survival of the reconstruction was assessed using revision surgery for major complications (fracture and nonunion) and removal of the reconstruction and amputation as endpoints indicating failure. Survival was determined according to the method of Kaplan-Meier. Statistical analysis was performed using the MedCalc statistical package (version 16.5, Ostend, Belgium).

This study was approved by our local institutional review board. All patients were informed that data from this study would be submitted for publication and gave their consent for participation.

\section{Results}

After a mean follow-up of 141 months (24 to 313), 18 patients were continuously disease-free $(78.2 \%)$. None had a local recurrence. Three patients $(13 \%)$ had a lung metastasis at a mean of 47 months (11 to 82 ). One was treated surgically by metastasectomy and was disease-free 83 months later. The other two received palliative 
treatment and died from metastases after a mean of 65 months (48 to 82) from their initial resection/reconstruction. One patient was alive with bony metastases that appeared 18 months after surgery. One patient committed suicide 34 months after the index operation.

Donor site complications were seen in four patients (17.4\%). Three children (seven, eight, and ten years of age at time of surgery) developed a valgus ankle deformity. In two, a spontaneous correction occurred after tibiofibular synostosis, while the third needed a tibial osteotomy. Data about the length of the residual fibula at the time of harvest were not available and no correlation analysis was possible. One patient needed surgical debridement for a wound dehiscence.

There were six cases of limb length discrepancy at the recipient site: the mean shortening was $3.2 \mathrm{~cm}$ (1.5 to 5.0). Five patients were treated with orthoses and the sixth with a lengthening nail. Two patients developed a valgus deformity of the knee at the recipient site; one was treated by epiphysiodesis. One patient developed an arteriovenous fistula which was successfully treated by embolization. A further patient developed a fracture through the osteoporotic femur above the reconstruction and was treated by plate fixation. One patient complained of hip pain from a protruding screw, which was removed. There were no deep infections at either the donor or recipient site.

Eight major complications occurred at the recipient site in seven patients (30.4\%) within four years and ten months from surgery; surgical revision was required in seven cases.

There were five fractures $(21.7 \%)$. These occurred at a mean time from the index operation of 33 months (13 to 58). Four occurred in type $\mathrm{C}$ reconstructions. In one case, a patient with screw-only fixation, the displaced fracture occurred after a severe injury. It healed spontaneously after closed reduction and cast immobilization. The remaining four patients were treated operatively. Revision surgery with open reduction and replacement of the hardware was needed in three cases, with autologous bone graft augmentation in one case. In one case, the previous implant was removed and a new type A reconstruction with allograft and VFG was carried out.

Three patients (13\%) developed a nonunion of the distal cortical osteotomy of the allograft; two of these were type A reconstructions. In each case, the nonunion healed after revision using additional autologous iliac crest bone graft.

At final follow-up, the mean MSTS93 score of the 22 surviving patients was $94 \%$ (73 to 100$)$.

The revision-free survival of the reconstructions, with failure due to fracture and nonunion requiring revision surgery as the endpoints, was $72.3 \%$ at five years; it remained unchanged until final follow-up (Fig. 5). The overall survival of the reconstructions, with removal of allograft and amputation as failure endpoints, was $94.4 \%$ at five, ten, and 15 years (Fig. 6). 


\section{Discussion}

Because of advances in chemotherapy, the survival of patients with a bone sarcoma has greatly improved. Since most patients with a primary bone tumour are young, a long-lasting reconstruction should be the aim of limb salvage surgery.

In our experience, biological reconstruction with a VFG is a reliable method of reconstruction after excision of an intercalary bone tumour from a long bone. $(10,11)$ Because its endosteal and periosteal blood supply is retained, a VFG retains its biological and mechanical properties, heals by primary union, and can hypertrophy in response to load.(26) The shape and size of the fibula allow it to be inserted into the medullary cavity of the femur, where it can be used concentrically with an allograft. It also allows the reconstruction of very large intercalary defects (up to $29 \mathrm{~cm}$ in our experience). We prefer to harvest the vascularized fibula from the contralateral leg for two reasons: first, to allow two different surgical teams to operate simultaneously, thereby decreasing the overall operating time; and second, to decrease the hypothetical risk of contamination of the donor site by tumour.

The femur is subject to the highest mechanical stresses in the entire skeleton. Consequently, an intercalary reconstruction with VFG alone can be mechanically insufficient until hypertrophy eventually occurs. For this reason, Capanna et al (24) introduced a new technique whereby the VFG was supplemented with a massive allograft. The theoretical basis for this was that during the first two years after surgery, the allograft maintains its mechanical strength and stability while the biological properties of the fibula allow for early union and improve internal repair of the allograft. After the second year from surgery, the internal repair of the allograft decreases its mechanical strength while the fibula progressively hypertrophies, strengthening the reconstruction. This technique has proved particularly useful in periarticular epiphyseal-sparing resection of the lower limb, allowing intercalary reconstruction even when only a very thin epiphyseal segment can be preserved. $(10,11)$

To our knowledge, this is the first study that just addresses reconstruction of the femur using a VFG and massive allograft after tumour resection. There are other reports that describe the use of a VFG to reconstruct the femur, salvage a limb, treat non-oncological conditions, $(27,28)$ or describe tumour resections of other long bones, including the humerus and tibia. $(8,9,13-16)$

This study has some limitations. It is a retrospective analysis of a 22 -year period, albeit based on a series of patients treated in a single institution by the same surgical team. There was no control group available to compare results. Finally, VFG and allograft reconstruction was undertaken using three different techniques (A, B, C) but the numbers remain too small to allow a comparative analysis.

We found that: first, the morbidity of the procedure was comparable with that of other reconstructive options of intercalary defects of the femur; second, the functional results were excellent with a mean MSTS score of 94\% (73 to 100); and third, biological reconstruction of an intercalary defect with VFG and allograft resulted in a durable and long-lasting restoration of the structure of the femur. 
There are several alternative options for reconstruction of an intercalary defect after resection of a diaphyseal bone tumour from the femur.

Modular prostheses are indicated for the reconstruction of an articular defect in the leg and have been used to treat intercalary defects in long bones. When the residual bone is too short to anchor a stem, new custom-made prostheses with epiphyseal anchorage and a hydroxyapatite-coated collar and plates have been used.(4,5) Good mid- to long-term functional outcomes (mean $87 \%$ MSTS score) have been noted with a revision-free survival of the implant of $85 \%$ at five years, and $68 \%$ at ten years.(5)

Massive allografts are one of the most popular methods of reconstructing an intercalary defect in the femur after resection of a bone tumour. They allow the restoration of any length of defect and, in our unit, we prefer to use an isolated allograft when the length of intercalary resection is too long to accept an autologous fibula. Unfortunately, the internal repair of the allograft is a slow and incomplete process, even several years after implantation, and the risk of complications such as nonunion and fracture is high. $(6,29)$

A lower fracture rate $(17 \%)$ than that seen in our series was reported by AponteTinao et al6 in a study of isolated intercalary femoral allografts, but no fracture healing was seen. In all cases except one, the fractured allografts were removed (eight had another intercalary graft, one had an osteoarticular allograft, and four had endoprostheses). In the remaining case, revision of plating and struct allograft was used without removing the previous allograft. The survival rate of a femoral allograft, taking the removal of the allograft or amputation as the endpoint, was $85 \%$ at five years and $76 \%$ at ten years. 6 In our series, four out of five fractures healed (three after surgical revision and one after conservative treatment). Only one patient had their implant removed for fracture and a further reconstruction.

Distraction osteogenesis has been used to reconstruct intercalary defects of the femur after bone tumour resection with acceptable results.(2,3) Considering the long duration of the treatment and its morbidity, the authors concluded that the procedure is only indicated for segmental defects of $15 \mathrm{~cm}$ or less.

In our series, intercalary resection and reconstruction with a VFG and allograft was reserved for non-bulky diaphyseal or metadiaphyseal tumours of the femur. In patients with an osteosarcoma or Ewing's sarcoma, it was only undertaken in those who had a favourable response to preoperative chemotherapy. A wide resection was achieved in all cases: there was no local recurrence. In other reports of intercalary reconstruction of the femur, the rate of local recurrence ranged between $0 \%$ and $20 \% \cdot(2,3,5,6,8,13-16)$

Major complications at the site of reconstruction occurred in $30.4 \%$ of patients, with all but one requiring revision surgery. The rate of fracture was high (21.7\%), but healing was seen in four out of five cases, which confirms the biological potential of the vascularized graft. Fractures were much more frequent in type $\mathrm{C}$ reconstructions, suggesting that opening the anterior cortex of the allograft may predictably decrease 
its mechanical strength. The rate of nonunion was lower (13\%) than in other series of isolated massive allograft reconstruction, suggesting a positive effect of the VFG on the ability of the allograft unite and undergo internal repair. Two of the three nonunions occurred in type A reconstructions at the site of the distal cortical diaphyseal osteotomy, indicating that positioning the fibula in parallel was less effective in promoting union of the allograft than a concentric arrangement. For each type of reconstruction, fixation with a bridging plate is recommended to decrease the risk of fracture and nonunion.

All complications occurred within five years of the index surgery, suggesting that union of the graft, its internal repair, and fibular hypertrophy may all improve the mechanical strength of the implant with time, resulting in a biological reconstruction that may last a lifetime (Figs 7a to 7d).

We had a robust prophylactic policy and did not see any deep infection. In the femur, after an intercalary resection, adequate soft-tissue coverage of the reconstruction is usually achieved and the risk of infection is lower than that in sites such as the proximal tibia. In the literature, the infection rate for intercalary reconstruction of the femur is reported as being between $0 \%$ and $25 \%$ (Table II).

Revision-free survival of the implant was $72.3 \%$ at five years; it remained unchanged at ten and 15 years. The overall survival, using implant removal or amputation as the endpoint, was $94.4 \%$ at five, ten, and 15 years. Valgus deformity of the ankle can be expected as a complication of vascularized fibula harvest in the growing child. Preventive tibiofibular screw fixation is advisable in children if the residual fibula is less than $6 \mathrm{~cm}$ in length.

Functional recovery was slow; full weight-bearing without a brace was only allowed after a mean of 13 months ( 7 to 26). More than half the patients wore the ischialbearing brace for more than one year after surgery until union of the osteotomies had occurred. With biological reconstruction, it must be appreciated that the prolonged use of cumbersome braces to protect weight-bearing can reduce the quality of life of the patient. The mean MSTS score for functional evaluation was $94 \%$ (73 to 100), which is higher than that reported in other comparable studies (Table II).

In conclusion, biological reconstruction of the femur using an autogenous VFG and massive allograft is an effective method of reconstructing the defect left after resection of an intercalary bone tumour. Once five years had elapsed from surgery, no further revision surgery was needed, suggesting that the mechanical strength of the biological reconstruction improves with time, decreasing the risk of complications. Eventually, this technique may result in a reconstruction that lasts a lifetime. Because of the prolonged period of rehabilitation and protected weight-bearing, biological intercalary reconstruction would seem to be indicated in patients with a favourable prognosis, a non-bulky tumour and a good response to preoperative chemotherapy. 


\section{References}

1. Capanna R, Scoccianti G, Frenos F, et al. What was the survival of megaprostheses in lower limb reconstructions after tumor resections? Clin Orthop Relat Res 2015;473:820-830.

2. Watanabe K, Tsuchiya H, Yamamoto N, et al. Over 10-year follow-up of functional outcome in patients with bone tumors reconstructed using distraction osteogenesis. J Orthop Sci 2013;18:101-109.

3. Demiralp B, Ege T, Kose O, Yurttas Y, Basbozkurt M. Reconstruction of intercalarybone defects following bone tumor resection with segmental bone transport using an Ilizarov circular external fixator. J Orthop Sci 2014;19:1004-1011.

4. Aldlyami E, Abudu A, Grimer RJ, Carter SR, Tillman RM. Endoprosthetic replacement of diaphyseal bone defects. Long-term results. Int Orthop 2005;29:25-29.

5. Hanna SA, Sewell MD, Aston WJ, et al. Femoral diaphyseal endoprosthetic reconstruction after segmental resection of primary bone tumours. J Bone Joint Surg [Br] 2010;92-B:867-874.

6. Aponte-Tinao L, Farfalli GL, Ritacco LE, Ayerza MA, Muscolo DL. Intercalary femur allografts are an acceptable alternative after tumor resection. Clin Orthop Relat Res 2012;470:728-734.

7. Gupta S, Kafchinski LA, Gundle KR, et al. Intercalary allograft augmented withintramedullary cement and plate fixation is a reliable solution after resection of a diaphyseal tumour. Bone Joint $J$ 2017;99-B:973-978.

8. Eward WC, Kontogeorgakos V, Levin LS, Brigman BE. Free vascularized fibular graft reconstruction of large skeletal defects after tumor resection. Clin Orthop Relat Res 2010;468:590-598.

9. Hilven PH, Bayliss L, Cosker T, et al. The vascularised fibular graft for limb salvage after bone tumour surgery: a multicentre study. Bone Joint J 2015;97-B:853-861.

10. Capanna R, Campanacci DA, Belot $\mathbf{N}$, et al. A new reconstructive technique for intercalary defects of long bones: the association of massive allograft with vascularized fibular autograft. Longterm results and comparison with alternative techniques. Orthop Clin North Am 2007;38:51-60.

11. Abed YY, Beltrami G, Campanacci DA, et al. Biological reconstruction after resection of bone tumours around the knee: long-term follow-up. J Bone Joint Surg [Br] 2009;91-B:1366-1372.

12. Innocenti M, Abed YY, Beltrami G, et al. Biological reconstruction after resection of bone tumors of the proximal tibia using allograft shell and intramedullary free vascularized fibular graft: long-term results. Microsurgery 2009;29:361-372.

13. Li J, Wang Z, Guo Z, et al. The use of allograft shell with intramedullary vascularized fibula graft for intercalary reconstruction after diaphyseal resection for lower extremity bony malignancy. J Surg Oncol 2010;102:368-374.

14. Rabitsch K, Maurer-Ertl W, Pirker-Frühauf U, Wibmer C, Leithner A. Intercalary reconstructions with vascularised fibula and allograft after tumour resection in the lower limb. Sarcoma 2013;2013:160295. 
15. Weichman KE, Dec W, Morris CD, Mehrara BJ, Disa JJ. Lower extremity osseous oncologic reconstruction with composite microsurgical free fibula inside massive bony allograft. Plast Reconstr Surg 2015;136:396-403.

16. Houdek MT, Wagner ER, Stans AA, et al. What Is the outcome of allograft and intramedullary free fibula (Capanna technique) in pediatric and adolescent patientswith bone tumors? Clin Orthop Relat Res 2016;474:660-668.

17. Manfrini M, Innocenti M, Ceruso M, Mercuri M. Original biological reconstruction of the hip in a 4-year-old girl. Lancet 2003;361:140-142.

18. Chang DW, Fortin AJ, Oates SD, Lewis VO. Reconstruction of the pelvic ring with vascularized double-strut fibular flap following internal hemipelvectomy. Plast Reconstr Surg 2008;121:1993-2000.

19. Ackerman DB, Rose PS, Moran SL, et al. The results of vascularized-free fibular grafts in complex spinal reconstruction. J Spinal Disord Tech 2011;24:170-176.

20. Emori M, Kaya M, Irifune H, et al. Vascularised fibular grafts for reconstruction of extremity bone defects after resection of bone and soft-tissue tumours : a single institutional study of 49 patients. Bone Joint J 2017;99-B:1237-1243.

21. Houdek MT, Bayne CO, Bishop AT, Shin AY. The outcome and complications of vascularised fibular grafts. Bone Joint J 2017;99-B:134-138.

22. Taylor GI, Miller GD, Ham FJ. The free vascularized bone graft. A clinical extension of microvascular techniques. Plast Reconstr Surg 1975;55:533-544.

23. Weiland AJ, Daniel RK, Riley LHJr. Application of the free vascularized bone graft in the treatment of malignant or aggressive bone tumors. Johns Hopkins Med J 1977;140:85-96.

24. Capanna R, Bufalini C, Campanacci M. A new technique for reconstruction of large metadiaphyseal bone defects: A combined graft (allograft shell plus vascularized fibula). Orthop Traumatol 1993;2:159-177.

25. Enneking WF, Dunham W, Gebhardt MC, Malawar M, Pritchard DJ. A system for the functional evaluation of reconstructive procedures after surgical treatment of tumors of the musculoskeletal system. Clin Orthop Relat Res 1993;286:241-246.

26. Manfrini M, Vanel D, De Paolis M, et al. Imaging of vascularized fibula autograft placed inside a massive allograft in reconstruction of lower limb bone tumors. AJR Am J Roentgenol 2004;182:963-970.

27. Chang DW, Weber KL. Use of a vascularized fibula bone flap and intercalary allograft for diaphyseal reconstruction after resection of primary extremity bone sarcomas. Plast Reconstr Surg 2005;116:1918-1925.

28. Campanacci DA, Puccini S, Caff G, et al. Vascularised fibular grafts as a salvage procedure in failed intercalary reconstructions after bone tumour resection of the femur. Injury 2014;45:399-404.

29. Donati D, Di Liddo M, Zavatta M, et al. Massive bone allograft reconstruction in high-grade osteosarcoma. Clin Orthop Relat Res 2000;377:186-194. 


\begin{tabular}{|c|c|c|c|c|c|c|c|c|c|c|c|c|c|}
\hline Patient & $\begin{array}{l}\text { Age } \\
\text { (yrs) }\end{array}$ & Gender & Diagnosis & $\begin{array}{l}\text { Length of } \\
\text { VFG }(\mathrm{cm})\end{array}$ & Fixation & $\begin{array}{l}\text { Graft } \\
\text { assembling } \\
\text { type }\end{array}$ & $\begin{array}{l}\text { Follow-up } \\
\text { (mths) }\end{array}$ & $\begin{array}{l}\text { Complications, } \\
\text { donor site }\end{array}$ & $\begin{array}{l}\text { Complications, } \\
\text { recipient site }\end{array}$ & Treatment of complications & $\begin{array}{l}\text { Oncological } \\
\text { relapse }\end{array}$ & $\begin{array}{l}\text { Oncological } \\
\text { outcome }\end{array}$ & MSTS (\%) \\
\hline 1 & 10 & Male & os & 12 & $\begin{array}{l}\text { Plate proximally and } \\
\text { screw distally }\end{array}$ & B & 111 & $\begin{array}{l}\text { Ankle valgus } \\
\text { deformity }\end{array}$ & Shortening $(4 \mathrm{~cm})$ & $\begin{array}{l}\text { Tibiofibular synostosis (19 mths) and } \\
\text { epiphysiodesis (40 mths), lengthening } \\
(107 \mathrm{mths})\end{array}$ & & CDF & 93 \\
\hline 2 & 8 & Male & ES & 17 & Bridging plate & A & 300 & & Nonunion & $\begin{array}{c}\text { Autogenous bone grafts } \\
(12 \mathrm{mths})\end{array}$ & & CDF & 100 \\
\hline 3 & 38 & Female & OS & 18 & Bridging plate & A & 285 & & & & & CDF & 90 \\
\hline 4 & 12 & Male & os & 12 & $\begin{array}{l}\text { Plate proximally and } \\
\text { screw distally }\end{array}$ & c & 306 & & $\begin{array}{l}\text { Fracture with failure } \\
\text { of VFG and } \\
\text { shortening }(3 \mathrm{~cm})\end{array}$ & $\begin{array}{l}\text { Implant removal and new allograft } \\
\text { with VFG type A (41 mths) and } \\
\text { orthotics }\end{array}$ & & CDF & 100 \\
\hline 5 & 11 & Male & OS & 24,5 & Bridging plate & A & 241 & & $\begin{array}{c}\text { Knee valgus deformity } \\
\text { and } \\
\text { dysmetria }(3 \mathrm{~cm}) \\
\end{array}$ & $\begin{array}{l}\text { Epiphysiodesis ( } 30 \\
\text { mths) and orthotics }\end{array}$ & & CDF & 93 \\
\hline 6 & 13 & Male & OS & 14 & Bridging plate & B & 48 & $\begin{array}{l}\text { Wound } \\
\text { dehiscence }\end{array}$ & $\begin{array}{l}\text { Ipsilateral femoral } \\
\text { fracture }\end{array}$ & $\begin{array}{l}\text { Surgical debridement (1 month) and } \\
\text { plate fixation (12 mths and } \\
25 \mathrm{mths})\end{array}$ & MET (48 mths) & DOD & 86 \\
\hline 7 & 14 & Male & OS & 29 & Bridging plate & c & 106 & & $\begin{array}{c}\text { Fracture and } \\
\text { hardware failure, and } \\
\text { shortening } \\
(1.5 \mathrm{~cm})\end{array}$ & $\begin{array}{l}\text { New ORIF ( } 38 \text { mths) } \\
\text { and orthotics }\end{array}$ & MET (11 mths) & NED & 73 \\
\hline 8 & 8 & Male & OS & 13 & Bridging plate & A & 286 & $\begin{array}{c}\text { Ankle valgus } \\
\text { deformity }\end{array}$ & & Osteotomy (35 mths) & & CDF & 96 \\
\hline 9 & 31 & Male & OS & 15 & Bridging plate & A & 82 & & & & MET (82 mths) & DOD & 83 \\
\hline 10 & 13 & $\begin{array}{l}\text { Female } \\
\end{array}$ & OS & 22 & Bridging plate & A & 264 & & & & & CDF & 100 \\
\hline 11 & 14 & Male & os & 16 & Bridging plate & c & 34 & & $\begin{array}{c}\begin{array}{c}\text { Fracture and } \\
\text { hardware failure }\end{array} \\
\text { hen }\end{array}$ & New ORIF (13 mths) & & DOC & $\mathrm{Na}$ \\
\hline 12 & 15 & Female & DT & 18 & Bridging plate & C & 140 & & & & & $\mathrm{CDF}$ & 90 \\
\hline 13 & 13 & Male & os & 16 & Screws & c & 313 & & $\begin{array}{l}\text { Fracture after } \\
\text { severe trauma }\end{array}$ & Cast (15 mths) & & CDF & 100 \\
\hline 14 & 5 & Female & ES & 17 & Bridging plate & A & 120 & & & & & $\mathrm{CDF}$ & 100 \\
\hline 15 & 7 & Male & ES & 18 & Bridging plate & B & 109 & $\begin{array}{c}\text { Ankle valgus } \\
\text { deformity }\end{array}$ & AV fistula & $\begin{array}{l}\text { Embolization (24 mths) and } \\
\text { tibiofibular synostosis ( } 83 \mathrm{mths} \text { ) }\end{array}$ & & $\mathrm{CDF}$ & 96 \\
\hline 16 & 22 & Male & CS & 20 & Bridging plate & A & 98 & & $\begin{array}{c}\text { Nonunion, fracture } \\
\text { and hardware failure, } \\
\text { and shortening }(2.5 \\
\mathrm{cm})\end{array}$ & $\begin{array}{l}\text { Autologous bone graft (11 mths) and } \\
\text { plate removal, nail fixation and } \\
\text { autologous bone graft ( } 58 \mathrm{mths} \text { ), and } \\
\text { orthotics }\end{array}$ & & CDF & 95 \\
\hline 17 & 40 & Male & CS & 20 & Bridging plate & A & 169 & & & & & CDF & 100 \\
\hline 18 & 12 & Male & ES & 18 & Bridging plate & A & 58 & & $\begin{array}{l}\text { Knee valgus deformity } \\
\text { and shortening } 5 \mathrm{~cm}\end{array}$ & No treatment and orthotics & & $\mathrm{CDF}$ & 96 \\
\hline 19 & 14 & Female & ES & 25 & Bridging plate & c & 55 & & $\begin{array}{l}\text { Hip pain with } \\
\text { long screw }\end{array}$ & Screw removal (18 mths) & & CDF & 100 \\
\hline 20 & 10 & Female & ES & 15 & Bridging plate & B & 37 & & & & & CDF & 96 \\
\hline 21 & 40 & Female & LMS & 15 & Bridging plate & B & 31 & & & & MET (18 mths) & AWD & 93 \\
\hline 22 & 12 & Female & ES & 23 & $\begin{array}{c}\text { Bridging plate and } \\
\text { distal antirotational } \\
\text { plate }\end{array}$ & B & 25 & & Nonunion & $\begin{array}{l}\text { New ORIF and autologous bone graft } \\
\text { (12 mths) }\end{array}$ & & CDF & 93 \\
\hline 23 & 10 & Male & ES & 20 & $\begin{array}{c}\text { Bridging plate and } \\
\text { proximal antiroational } \\
\text { plate }\end{array}$ & B & 24 & & & & & CDF & 100 \\
\hline
\end{tabular}

Table I - Patient characteristics. VFG = vascularized fibular graft; MSTS = Musculoskeletal Tumor Society; OS = osteosarcoma; CDF = continuously disease-free; ES = Ewing's sarcoma; MET = metastases; DOD = dead of disease; ORIF = open reduction internal fixation; NED = Not evident disease after local recurrence or excision of metastases; $D O C=$ dead of other cause; DT = desmoid tumour; $A V=$ arteriovenous; $C S=$ chondrosarcoma; LMS = leiomyosarcoma; AWD = alive with disease 


\begin{tabular}{|c|c|c|c|c|c|c|}
\hline Authors & Patients & $\begin{array}{l}\text { Mean follow- } \\
\text { up (months }\end{array}$ & $\begin{array}{l}\text { Type of } \\
\text { reconstruction }\end{array}$ & Complications (\%) & Survival (\%) & MSTS (\%) \\
\hline $\begin{array}{l}\text { Hanna et } a l^{5} \\
\quad(2010)\end{array}$ & 23 & 97 & Endoprosthesis & $\begin{array}{c}\text { Deep infection (4); } \\
\text { prosthesis breakage (8); } \\
\text { periprosthetic fracture (4); } \\
\text { loosening (4) }\end{array}$ & $\begin{array}{l}85 \text { at } 5 \text { yrs; } \\
68 \text { at } 10 \text { yrs }\end{array}$ & 87 \\
\hline $\begin{array}{l}\text { Aponte-Tinao et } \\
\mathrm{al}^{6}(2011)\end{array}$ & 83 & 61 & Allograft & $\begin{array}{c}\text { Deep infection (1); } \\
\text { nonunion (24); } \\
\text { fracture (17) }\end{array}$ & $\begin{array}{l}85 \text { at } 5 \text { yrs; } \\
76 \text { at } 10 y r s\end{array}$ & 90 \\
\hline $\begin{array}{c}\text { Watanabe et al } \\
\text { (2013) }\end{array}$ & 7 & 191 & $\begin{array}{l}\text { Distraction } \\
\text { osteogenesis }\end{array}$ & $\begin{array}{l}\text { Delayed union (28.5); } \\
\text { delayed consolidation (14); } \\
\text { callus fracture (14) }\end{array}$ & N/A & 94 \\
\hline $\begin{array}{l}\text { Demiralp et } \mathrm{al}^{3} \\
\text { (2014) }\end{array}$ & 5 & N/A & $\begin{array}{l}\text { Distraction } \\
\text { osteogenesis }\end{array}$ & $\begin{array}{c}\text { Pin tract infection (60); } \\
\text { skin invagination (20); } \\
\text { malunion (16); } \\
\text { delayed union (40); } \\
\text { fracture (0) }\end{array}$ & N/A & 89 \\
\hline $\begin{array}{c}\text { Eward et al }^{8} \\
\quad(2010)\end{array}$ & 9 & 77 & VFG & $\begin{array}{l}\text { Deep infection (11); } \\
\text { nonunion (unclear); } \\
\text { fracture (22) }\end{array}$ & N/A & $N / A$ \\
\hline Li et al ${ }^{13}(2010)$ & 5 & 36 & VFG and allograft & $\begin{array}{c}\text { Superficial infection (20); } \\
\text { loose and breakage of } \\
\text { screws (20); nonunion (0); } \\
\text { fracture (0) }\end{array}$ & N/A & 93 \\
\hline $\begin{array}{l}\text { Rabitsch et } \text { al }^{14} \\
\text { (2013) }\end{array}$ & 7 & N/A & VFG and allograft & $\begin{array}{c}\text { Deep infection (0); } \\
\text { nonunion (28.5); } \\
\text { fracture (57) }\end{array}$ & N/A & 94 \\
\hline $\begin{array}{l}\text { Weichman et al }{ }^{15} \\
\text { (2015) }\end{array}$ & 8 & 55 & VFG and allograft & $\begin{array}{c}\text { Infection (25); } \\
\text { nonunion (37.5); } \\
\text { fracture (25) }\end{array}$ & $\begin{array}{l}\text { N/A (2 femoral } \\
\text { implant removals) }\end{array}$ & $N / A$ \\
\hline $\begin{array}{l}\text { Houdek et al }{ }^{16} \\
\text { (2016) }\end{array}$ & 9 & N/A & VFG and allograft & $\begin{array}{c}\text { Deep infection (0); } \\
\text { nonunion (22); } \\
\text { fracture (unclear) }\end{array}$ & N/A & 91 \\
\hline Current study & 23 & 141 & VFG and allograft & $\begin{array}{l}\text { Deep infection (0); } \\
\text { nonunion (13); } \\
\text { fracture (21.7) }\end{array}$ & $\begin{array}{l}94.4 \text { at } 5 \text { yrs; } \\
94.4 \text { at } 10 \text { yrs }\end{array}$ & 94 \\
\hline
\end{tabular}

Table II - Review of the literature, comparing different studies involving intercalary femoral reconstruction after tumour surgery

MSTS = Musculoskeletal Tumor Society; N/A = not available; VFG = vascularized fibula graft 


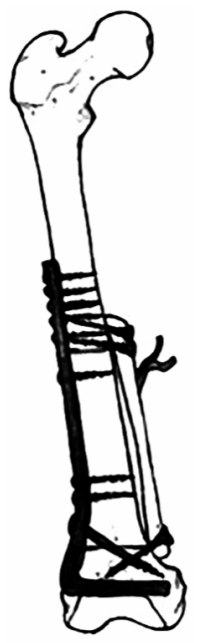

Fig. 1A

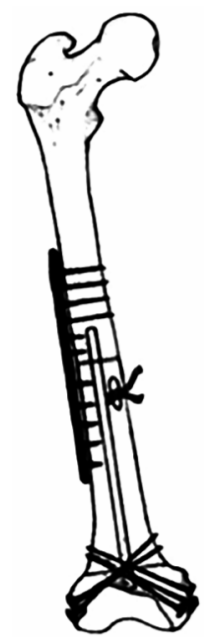

Fig. 1B

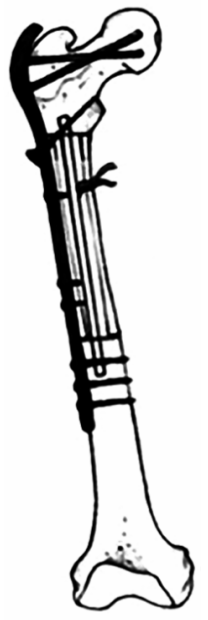

Fig. 1C

Diagram showing the three different methods of assembling the grafts: types A, B, and C (left to right).
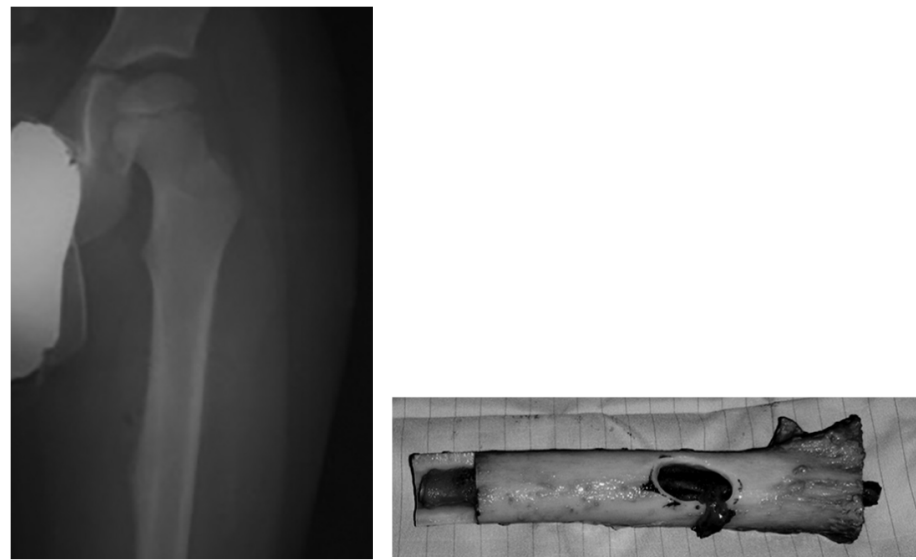

Fig. 3a

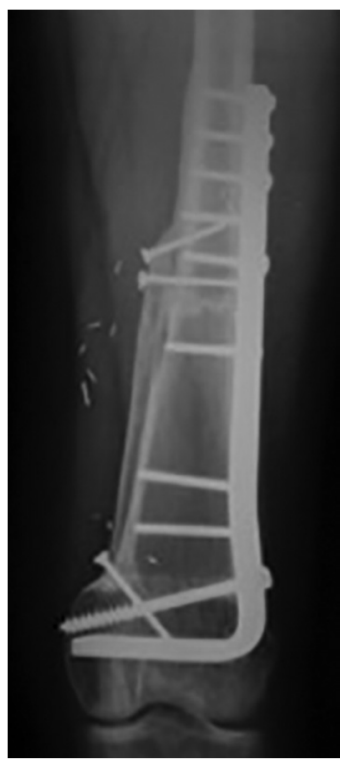

Fig. 2

Plain radiograph at three years' follow-up of a type $A$ Reconstruction after intercalary resection of an osteosarcoma in a 38-year-old woman.

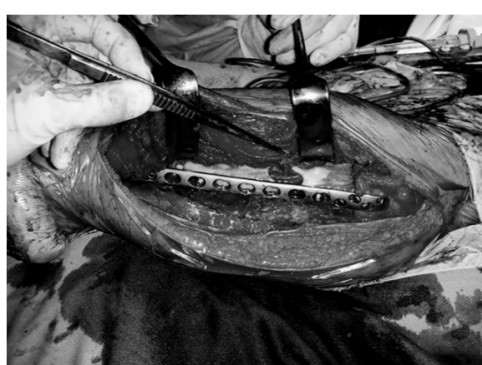

Fig. 3c

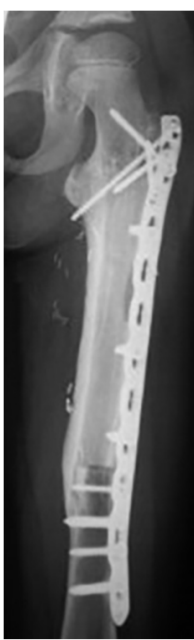

Fig. 3d

a) Radiograph showing a Ewing's sarcoma of the femur in a seven-year-old boy; b) photograph showing a type B reconstruction with the vascularized fibula graft inserted into the medullary canal of the allograft; the vascular pedicle is passed through an oval hole in the cortex; $c$ ) intraoperative view after plate fixation; and d) radiographic control at four years' follow-up. 


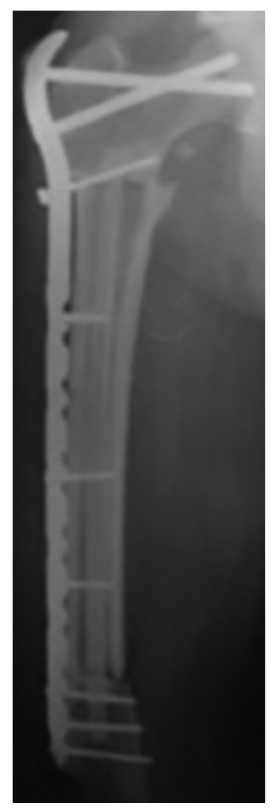

Fig. 4a

Fig. 4b

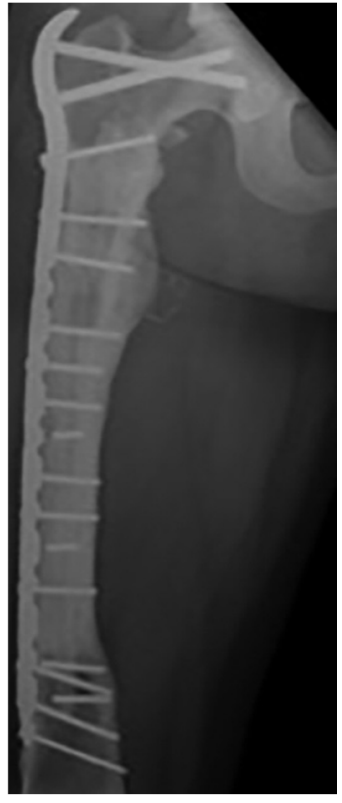

Fig. 4c fer restion of an osteosarcoma of the right femur in a 14-year-old male patient; b) fracture at 38 months treated with open reduction and internal fixation, with autologous bone grafting preserving the plate; and c) control at four years after fracture healing.

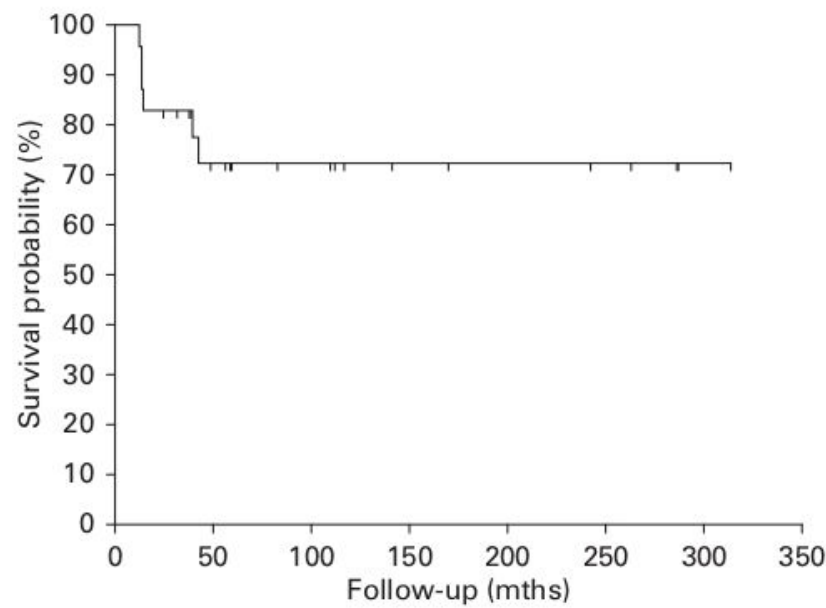

\section{Fig. 5}

Graph showing the revision-free survival of the reconstruction with fracture and nonunion as endpoints 


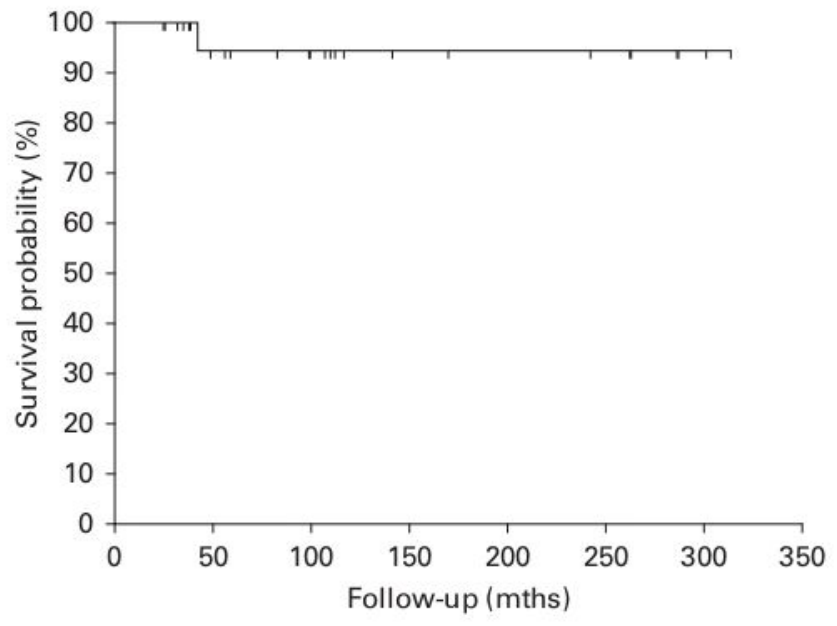

Fig. 6

Graph showing overall survival of the reconstruction with removal of the allograft and vascularized fibula graft and amputation as endpoints

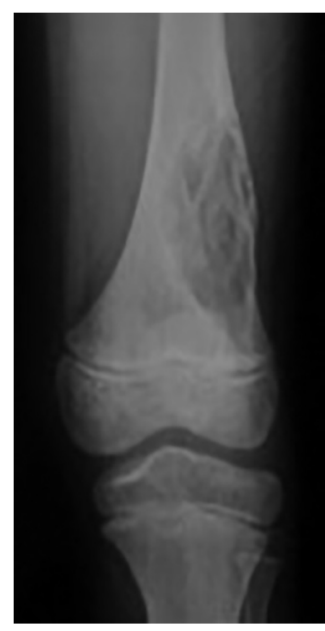

Fig. 7a and b) MRI showing an osteosarcoma of the distal femur without epiphyseal involvement in a ten-year-old boy.c) Intraoperative eight years' follow-up.
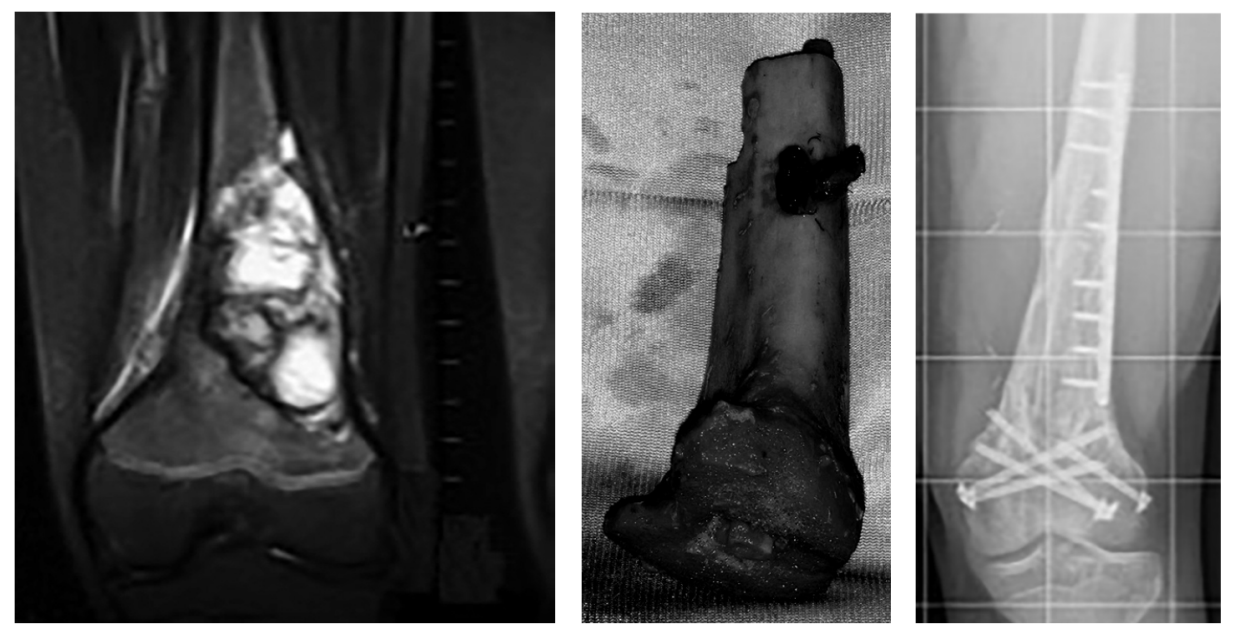

Fig. 7c

Fig. 7d 